DOI: $10.15593 / 2224-9354 / 2020.1 .18$

УДК $331.101 .3+331.108 .5$

Л.Н. Депутатова, Е.А. Севидова, Е.М. Юзькова

\author{
НЕМАТЕРИАЛЬНАЯ СИСТЕМА СТИМУЛИРОВАНИЯ \\ ПЕРСОНАЛА КАК ИНСТРУМЕНТ РАЗВИТИЯ \\ ЭМОЦИОНАЛЬНОГО ИНТЕЛЛЕКТА
}

\begin{abstract}
Рассмотрены основные подходы к формированию человеческого интеллекта, а также современные модели и представления об эмоциональном интеллекте. Определена основная цель, заложенная в формировании эмоционального интеллекта сотрудников предприятия. Описаны четыре основных компонента, составляющих эмоционального интеллекта: «Понимание себя», «Управление собой», «Понимание других» и «Управление другими». Также рассмотрена нематериальная система стимулирования как способ влияния на эмоциональный интеллект сотрудников. Авторами предлагается схема мотивационного механизма управления, существующего внутри любого предприятия. Представлен анализ принципов построения мотивационного механизма управления. Вследствие чего сделан вывод о необходимости подстраивать мотивацию под интересы конкретных сотрудников для того, чтобы она была действительно результативной и в полной мере развивала все элементы эмоционального интеллекта сотрудника. В ходе работы сделан вывод, что эмоциональный интеллект необходим в любой профессиональной деятельности, которая предполагает коммуникации с другими людьми. От уровня реализации эмоционального интеллекта зависит внедрение системы ценностей и установок, разделяемой персоналом организации в целом, поскольку именно эмоциональный интеллект является искусством управления эмоциями с целью рациональной организации труда. Механизм роста эмоционального интеллекта сотрудников компании зависит от желания проявлять инициативу, способности руководителя осознавать мотивы других людей и создавать необходимые условия для рабочей группы. Определяющим фактором мобилизации работников на выполнение задач, стоящих перед предприятием, является система нематериального стимулирования, которая нуждается в совершенствовании с учетом современных подходов, методик и тенденций производственного менеджмента.

Ключевые слова: эмоциональный интеллект, мотивация труда, стимулирование труда, управление персоналом, нематериальное стимулирование, система мотивации.
\end{abstract}

В настоящее время ввиду постоянных изменений и нестабильности становится необходимым развитие личностных качеств сотрудников для более эффективного функционирования организации. Эмоциональный интеллект это внутренний ресурс, подъемная сила для развития. Именно развитый эмоциональный интеллект дает возможность контролировать эмоции и увеличи-

(С Депутатова Л.Н., Севидова Е.А., Юзькова Е.М., 2020

Депутатова Людмила Николаевна - канд. экон. наук, доцент кафедры экономики и управления промышленным производством ФГБОУ ВО «Пермский национальный исследовательский политехнический университет», e-mail: milade@mail.ru.

Севидова Елизавета Александровна - студент гр. Э-15-1б, ФГБОУ ВО «Пермский национальный исследовательский политехнический университет», e-mail: liza1163a@rambler.ru.

Юзькова Екатерина Михайловна - студент гр. Э-15-1б, ФГБОУ ВО «Пермский национальный исследовательский политехнический университет», e-mail: katya.yuzkowa@yandex.ru. 
вает продуктивность, а также помогает в решении задач. От уровня реализации эмоционального интеллекта зависит внедрение системы ценностей и установок, разделяемой сотрудниками организации в целом.

Для характеристики человека в деятельности организации используется понятие «трудовой потенциал», означающее возможности, силу, источники и средства, которые могут быть использованы для решения определенных задач.

Появлению в 1990-е гг. понятия «эмоциональный интеллект» (от англ. emotional intelligence) способствовало постепенное изменение точки зрения на соотношение эмоциональных и познавательных процессов. Оформление термина «эмоциональный интеллект» явилось результатом развития представлений о взаимосвязях когнитивных и аффективных процессов [1].

Современные понятия об эмоциональном интеллекте представлены в табл. 1 [2].

Таблица 1

Современные модели эмоционального интеллекта

\begin{tabular}{|c|c|c|c|}
\hline Определение & Автор & Модель & Особенности \\
\hline $\begin{array}{l}\text { Способность воспринимать } \\
\text { и понимать проявления } \\
\text { личности, выражаемые в } \\
\text { эмоциях, управлять эмо- } \\
\text { циями на основе интеллек- } \\
\text { туальных процессов }\end{array}$ & $\begin{array}{l}\text { П. Сэловей, } \\
\text { Дж. Майер, } \\
\text { Д. Карузо } \\
\end{array}$ & $\begin{array}{l}\text { Модель } \\
\text { нального интеллекта } \\
\text { Майера - Сэловея - } \\
\text { Карузо (модель спо- } \\
\text { собностей) }\end{array}$ & $\begin{array}{l}\text { Авторы обращают } \\
\text { внимание на способ- } \\
\text { ность контролировать } \\
\text { выражаемые челове- } \\
\text { ком эмоции }\end{array}$ \\
\hline $\begin{array}{l}\text { Все некогнитивные способ- } \\
\text { ности, знания и компетент- } \\
\text { ность, дающие человеку } \\
\text { возможность } \\
\text { справляться с рспешно } \\
\text { жизненными ситуациями } \\
\end{array}$ & Р. Бан-Он & $\begin{array}{l}\text { Модель социально- } \\
\text { го и эмоционально- } \\
\text { го интеллекта Руве- } \\
\text { на Бар-Она (ESI) }\end{array}$ & $\begin{array}{l}\text { Авторами выделено } \\
\text { качество компетент- } \\
\text { ности, формируемое } \\
\text { в человеке на основе } \\
\text { некогнитивных спо- } \\
\text { собностей }\end{array}$ \\
\hline $\begin{array}{l}\text { Способность осознавать } \\
\text { свои эмоции и эмоции дру- } \\
\text { гих, чтобы мотивировать } \\
\text { себя и других и хорошо } \\
\text { управлять эмоциями наеди- } \\
\text { не с собой и при взаимодей- } \\
\text { ствии с другими }\end{array}$ & Д. Гоулман & $\begin{array}{l}\text { Смешанная модель } \\
\text { Гоулмана }\end{array}$ & $\begin{array}{lr}\text { Автор } & \text { фокусирует } \\
\text { внимание } & \text { на способ- } \\
\text { ности мотивирования } \\
\text { людей } \\
\text { проявляемой эмпатия }\end{array}$ \\
\hline
\end{tabular}

В настоящем исследовании под эмоциональным интеллектом мы будем понимать способность человека распознавать эмоции, понимать намерения, мотивацию и желания других людей и свои собственные, а также способность управлять своими эмоциями и эмоциями других людей в целях решения практических задач. Компоненты эмоционального интеллекта разбиты на четыре основные категории и приведены в табл. 2 [3]. Каждая из этих категорий описывает определенные области способностей человека. 
Компоненты эмоционального интеллекта

\begin{tabular}{|c|l|l|}
\hline $\begin{array}{c}\text { № } \\
\text { п/п }\end{array}$ & $\begin{array}{l}\text { Компоненты эмоциональ- } \\
\text { ного интеллекта }\end{array}$ & \multicolumn{1}{|c|}{ Состав компонентов эмоционального интеллекта } \\
\hline 1 & $\begin{array}{l}\text { Понимание себя (самопо- } \\
\text { знание) }\end{array}$ & $\begin{array}{l}\text { Способность различать и интерпретировать собст- } \\
\text { венные настроения, эмоции, порывы, а также их } \\
\text { влияние на других людей }\end{array}$ \\
\hline 2 & $\begin{array}{l}\text { Управление собой (само- } \\
\text { регуляция) }\end{array}$ & $\begin{array}{l}\text { Способность регулировать свои эмоциональные } \\
\text { реакции и состояния, управлять своим настроением }\end{array}$ \\
\hline 3 & $\begin{array}{l}\text { Понимание других (соци- } \\
\text { альная чуткость, эмпатия) }\end{array}$ & $\begin{array}{l}\text { Способность понимать эмоциональное состояние } \\
\text { людей }\end{array}$ \\
\hline 4 & $\begin{array}{l}\text { Управление эмоциями } \\
\text { других и отношениями } \\
\text { (социальная умелость) }\end{array}$ & $\begin{array}{l}\text { Умение воздействовать на эмоциональное состоя- } \\
\text { ние других людей и поддерживать отношения с ни- } \\
\text { ми вне зависимости от их изначальной предраспо- } \\
\text { ложенности к этому }\end{array}$ \\
\hline
\end{tabular}

Каждый элемент эмоционального интеллекта одинаково важен, однако для овладения этими навыками потребуется четкая последовательность действий.

Осознание собственных эмоций, т.е. саморефлексия, дает возможность для понимания своих мотивов и последствий принятия решений.

Способность контролировать свои эмоции появляется в результате осознания собственных чувств. Человек с развитым эмоциональным интеллектом понимает мотивацию других людей, быстро реагирует на ситуацию и не тратит силы на негативные переживания, т.е. сохраняет энергию [4].

Проявление эмпатии является важным навыком. Исследование института Карнеги выявило, что 85 \% историй финансового успеха происходит в результате применения навыков межличностного общения, умения вести переговоры. И лишь 15 \% благодаря исключительно профессиональным знаниям [5].

Четвертый элемент концепта эмоционального интеллекта - навык отношений - формируется автоматически, после прохождения первых трех ступеней, а именно: обучения осознанности, управления эмоциями и эмпатии. Люди могут обладать высоким интеллектом, но в то же время у них может быть низкий эмоциональный интеллект, они могут выполнять определенные задачи (например, заниматься компьютерным программированием), поэтому им не обязательно общаться с другими людьми, однако их способности существенно ограничены. В то же время у человека может быть очень не высокий интеллект, но при этом он может быть очень коммуникабельным. Как в первом, так и во втором случае люди не смогут справиться со сложными задачами, поскольку необходимо развивать оба интеллекта [6].

Эмоциональный интеллект необходим в любой профессиональной деятельности, которая предполагает коммуникации с другими людьми. Настрое- 
ния задают эмоциональный тонус организации, который существенно сказывается на результативности трудовой деятельности. Высокий эмоциональный тонус побуждает работников выполнять свои функции на максимально возможном уровне. По сути, эмоциональный интеллект служит инструментом реализации потенциала к саморазвитию и самореализации работника в труде и неразрывно связан с мотивацией [7, с. 4].

Мотивация труда является важным элементом, без которого в современной экономике ни одна система не может функционировать эффективно. Мотивация побуждает человека трудиться качественно, достигая целей, которые перед ним поставлены.

Под мотивацией мы понимаем сознательный выбор человека определенного поведения, зависящего от различных внутренних и внешних факторов.

Таким образом, мотивация - это создание системы воздействий на персонал с целью побуждения его к качественной трудовой деятельности. Трудовая мотивация является основным компонентом самосознания работника, который определяет его отношение и поведение в трудовой деятельности, его реакции на конкретные условия работы [8, с. 358]. По В.И. Герчикову, существует несколько основных видов стимулирования, которые направлены на активность работника: денежные; натуральные (предоставление жилья и др.); моральные; патернализм (забота о сотруднике); негативные (наказания, угрозы); организационные; карьерное развитие; участие в управлении $[9,10]$. Эффективная система мотивации должна объединять интересы и потребности работников с целями организации. Очевидным является тот факт, что высокая производительность труда и управление не возможны без грамотного влияния на мотивы работников. Проблема дефицита квалифицированных кадров существует в настоящее время во многих компаниях. Решением данной проблемы может быть создание такой системы мотивации, которая смогла бы повысить уровень эмоционального интеллекта сотрудников [11].

Однако материальных вознаграждений для привлечения и удержания высококвалифицированных специалистов недостаточно. В данном случае важную роль играет нематериальное стимулирование. Нематериальное стимулирование направлено на повышение лояльности персонала к организации одновременно со снижением издержек по компенсации их трудозатрат. Лояльность персонала, т.е. чувство преданности компании, и мотивация взаимосвязаны [12].

Лояльность в организации рассматривается как отражение психологического климата организации, а также как основа для системы безопасности компании. Эмоциональный интеллект же изначально влияет на те или иные внутренние мотивы человека, тем самым формируя лояльность сотрудника.

Нематериальное стимулирование сочетает в себе такие стимулы, как социальные, моральные и творческие. Среди других вознаграждений нематериальная мотивация обладает следующими особенностями [13]: 
1. Нематериальное стимулирование может только дополнять, а не заменять материальное. Поскольку при отсутствии приемлемой заработной платы моральное стимулирование не будет действовать в нужной степени.

2. Нематериальное стимулирование, как и материальное, предполагает определенные издержки, однако в отличие от материального вознаграждения, они являются минимальными.

3. Система мотивации должна быть разработана с учетом интересов и мнения руководства и штатных работников.

4. Самомотивация является лучшей мотивацией для человека.

Необходимо нанимать целеустремленных и заинтересованных в своей профессии работников, поскольку воздействовать на стимулы таких сотрудников будет намного проще.

Существует множество нематериальных методов стимулирования работников, формирующихся в зависимости от миссии, цели, структуры организации, а также от специфики выполняемых работ.

Основными методами являются [14, с. 100]:

1) обучение (тренинги, курсы повышения квалификации);

2) реализация творческого и инновационного потенциала (нестандартные задачи, конкурсы, возможность реализации новых проектов);

3) возможности карьерного роста;

4) признание и поощрение;

5) вовлечение в принятие решений;

6) социальная защищенность;

7) условия труда (комфортное рабочее место, атмосфера);

8) стабильность и надежность организации.

Однако методы нематериального стимулирования, которые подходят одной организации, нельзя в полной мере применять в другой, так как необходимо изучить мотивы работников, лежащие в основе их трудовой активности $[15,16]$. Необходимо подстраивать мотивацию под интересы конкретных сотрудников для того, чтобы она была действительно результативной и в полной мере развивала все элементы эмоционального интеллекта сотрудника.

Анализируя структуру эмоционального интеллекта через систему мотивации персонала предприятия, можно сделать выводы о влиянии мотивов и стимулов руководителя на систему управления персоналом. Мотивационный механизм управления предприятия представлен на рис. 1.

Задача мотивационного механизма предприятия состоит в том, чтобы сформировать или активизировать состояние личности, которое определяет, насколько эффективно и активно сотрудник готов действовать в определенной ситуации.

Принципы построения мотивационного механизма предприятия [17]:

- согласование со структурой и важностью целей;

- прозрачность, понятность, справедливость; 


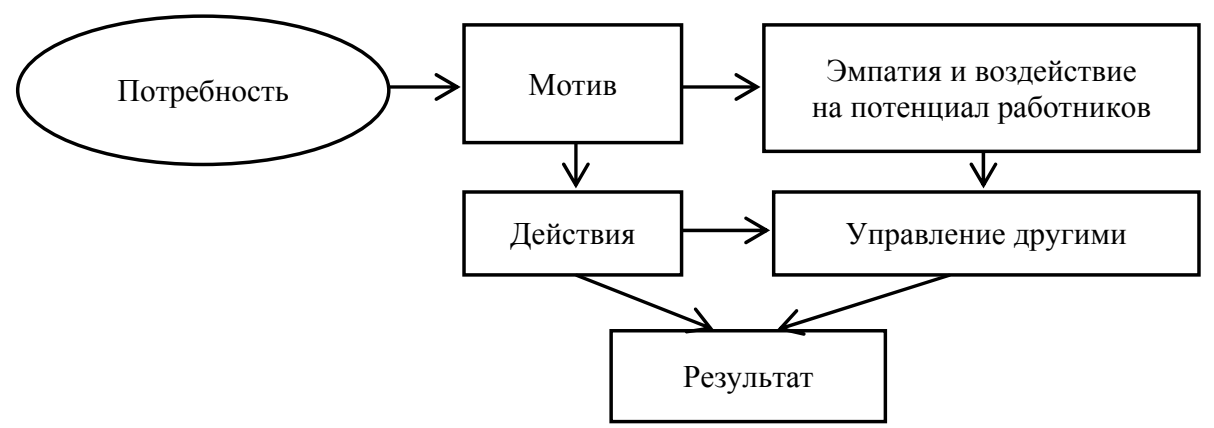

Рис. 1. Мотивационный механизм управления предприятия

- существование необходимых условий реализации;

- возможность корректировки;

- $\quad$ направленность на поддержку создания нового и на его принятие;

- $\quad$ взаимосвязь элементов при их обособленности.

Механизм мотивации на предприятии действует примерно следующим образом [18]:

1) возникает некая потребность;

2) происходит восприятие импульсов, идущих от нее;

3) анализируются ситуации с учетом ожиданий и стимулов;

4) далее следует актуализация, так называемое включение мотивов; в результате происходит отбор и актуализация части мотивов, а остальные отторгаются;

5) формируется определенное состояние личности (мотивированности), которое обеспечивает нужную интенсивность ее действий;

6) происходит определение и осуществление конкретных действий;

7) достигается определенный результат.

На большинстве предприятий применяют преимущественно так называемое мягкое стимулирование, основанное на побуждении к деятельности в соответствии с ценностным максимумом. Его инструментом является, например, социальный пакет благ, который в России сегодня часто значит больше, чем денежная заработная плата. Таким образом, мотивация сотрудников компании осуществляется, используя внутреннее и внешнее побуждение [19].

Внутренняя мотивация (самомотивация) сильно зависит от уровня эмоционального интеллекта сотрудников. Осознание работником своих мотивов и возможности реализовать свои потребности через стимулы организации позволяют активизировать желание и потенциал человека [20].

Внешняя мотивация (система мотивации работников предприятия) сильно зависит от уровня эмоционального интеллекта руководителя. Осознание руководителем мотивов своих подчиненных, поиск и предложение соответ- 
ствующих стимулов позволяют сформировать необходимые условия труда для эффективной интеллектуальной работы.

Механизм нематериального стимулирования предприятий должен быть направлен на повышение именно внутренней мотивации сотрудников, так как именно он способствует росту эмоционального интеллекта у всех работников с целью повышения эффективности работы предприятия (рис. 2).

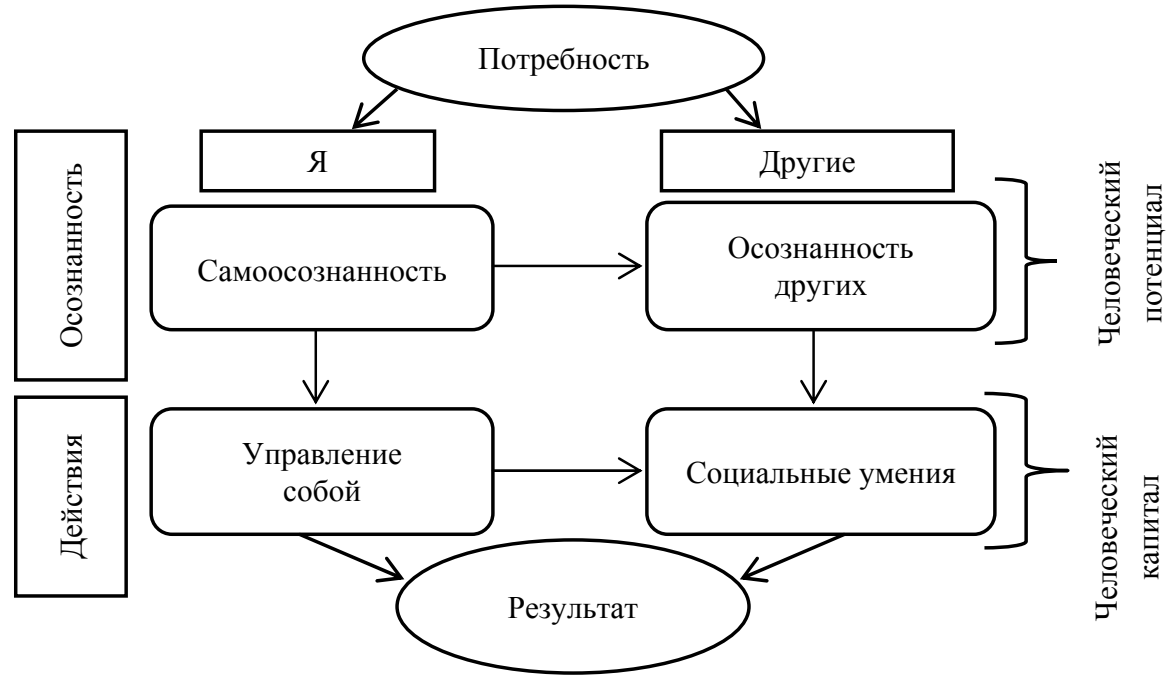

Рис. 2. Мотивационный механизм управления в соответствии с квадратами эмоционального интеллекта (EQ)

Путем увеличения способностей сотрудников происходит перерастание потенциала в человеческий капитал. Для этого необходимо наращивание интеллектуальной, информационной, культурной составляющих, что невозможно без роста и развития эмоционального интеллекта сотрудников. Соединение всех условий создания человеческого капитала осуществляется с помощью мотивации и стимулирования, которые невозможны без учета человеческих потребностей, осознание которых рождает мотивы и стимулы к совершенствованию способностей личности.

\section{Список литературы}

1. Базарсадаева Э.Ж. К вопросу об истории изучения эмоционального интеллекта // Вестник Бурятского государственного университета. Образование. Личность. Общество. - 2013. - № 5. - С. 24-31.

2. Гоулман Д. Эмоциональный интеллект. - М.: АСТ, 2008. - 478 с.

3. Осиновская И.В. Развитие нематериального стимулирования персонала в нефтесервесных компаниях // Теория и практика общественного развития. -2015 . - № 1. - С. 55-57. 
4. Мингалева Ж.А., Депутатова Л.Н. Двойственность мотивации интеллектуального труда работников // Вестник Пермского национального исследовательского политехнического университета. Социально-экономические науки. - 2016. - № 2. - С. 209-220.

5. Кравцова А.К. Влияние степени развития эмоционального интеллекта на эффективность управленческой деятельности // Известия Саратовского университета. Новая серия. Философия. Психология. Педагогика. - 2010. № 4. - С. 69-73.

6. Карузо Д., Сэловей П. Эмоциональный интеллект руководителя. Как развивать и применять. - СПб.: Питер, 2017. - 320 с.

7. Мингалева Ж.А., Депутатова Л.Н. Стимулирование интеллектуального труда как основа инновационного развития. - Пермь: Изд-во Перм. нац. исслед. политехн. ун-та, 2015. - 314 с.

8. Мингалева Ж.А., Старков Ю.В., Депутатова Л.Н. Модель оценки системы мотивации интеллектуальной деятельности // Теория и практика общественного развития. - 2013. - № 8. - С. 357-359.

9. Герчиков В.И. Управление персоналом: работник - самый эффективный ресурс компании. - М.: ИНФРА-М, 2008. - 282 с.

10. Нацыпаева Е.А. Повышение эффективности системы нематериального стимулирования организации за счет разработки гибкого социального пакета // Вестник Саратовского государственного социально-экономического университета. - 2017. - № 1. - С. 74-76.

11. Митрофанова А.Е. Современные системы нематериального стимулирования персонала организации // Вестник университета. - 2016. - № 11. C. 208-212.

12. От самоорганизации к саморазвитию: смена парадигмы менеджмента: моногр. / под ред. С.В. Комарова; Ин-т экономики УрО РАН. - Екатеринбург, 2013. - 257 с.

13. Пинк Д. Драйв: Что на самом деле нас мотивирует: пер. с англ. - М.: Альпина Паблишер, 2013. - 274 с.

14. Эльмурзаева Р.А. Реализация эмоционального интеллекта в трудовой деятельности // Вестник Томского государственного университета. Экономика. - 2011. - № 3 (15). - С. 95-102.

15. Панфилова А.П., Михальченко С.С. Развитие эмоционального интеллекта как составляющей социальной компетентности менеджеров // Человек и образование. -2013 . - № 1. - С. 66-70.

16. Полянова Л.М. Концепции эмоционального интеллекта в современной практике управления // Теория и практика общественного развития. 2015. - № 2. - С. 18-20.

17. Мингалева Ж.А., Депутатова Л.Н. Применимость различных форм мотивации для стимулирования труда интеллектуальных работников // Экономика и предпринимательство. - 2013. - № 10 (39). - С. 552-555. 
18. Рябова М.А. Актуальные проблемы создания эффективной системы нематериального стимулирования работников промышленных предприятий // Управление экономическими системами: электронный научный журнал. 2017. - № 1. - C. 3-5.

19. Скок С.П. Построение системы нематериального стимулирования // Вестник Омского университета. Экономика. - 2010. - № 1. - С. 103-105.

20. Шишкина К.А., Депутатова Л.Н. Совершенствование системы нематериальной мотивации работников ООО «ЛУКОЙЛ-Пермь» // Вестник Пермского национального исследовательского политехнического университета. Социально-экономические науки. - 2018. - № 1. - С. 198-209.

\section{References}

1. Bazarsadaeva E.Zh. K voprosu ob istorii izucheniia emotsional'nogo intellekta [To the issue of the history of emotional intellect study]. Vestnik Buriatskogo gosudarstvennogo universiteta. Obrazovanie. Lichnost'. Obshchestvo, 2013, no. 5, pp. 24-31.

2. Goleman D. Working with emotional intelligence (Russ.ed.: Goulman D. Emotsional'nyi intellekt. Moscow, AST, 2008, 478 p.).

3. Osinovskaia I.V. Razvitie nematerial'nogo stimulirovaniia personala $\mathrm{v}$ nefteservesnykh kompaniiakh [Development of non-financial motivation of personnel in the oil field service companies]. Teoriia i praktika obshchestvennogo razvitiia, 2015, no. 1, pp. 55-57.

4. Mingaleva Zh.A., Deputatova L.N. Dvoistvennost' motivatsii intellektual'nogo truda rabotnikov [Duality of intellectual work motivation in workers]. PNRPU Sociology and Economics Bulletin, 2016, no. 2, pp. 209-220.

5. Kravtsova A.K. Vliianie stepeni razvitiia emotsional'nogo intellekta na effektivnost' upravlencheskoi deiatel'nosti [The correlation of emotional intelligence qualities and management effectiveness]. Izvestiia Saratovskogo universiteta. Novaia seriia. Filosofiia. Psikhologiia. Pedagogika, 2010, no. 4, pp. 69-73.

6. Caruzo D., Salovey P. The emotionally intelligence manager. How to develop and use the four key emotional skills of leadership (Russ. ed.: Karuzo D., Selovei P. Emotsional'nyi intellekt rukovoditelia. Kak razvivat' i primeniat'. St. Petersburg, Piter, 2017, 320 p.).

7. Mingaleva Zh.A., Deputatova L.N. Stimulirovanie intellektual'nogo truda kak osnova innovatsionnogo razvitiia [Stimulation of intellectual work as the basis of innovative development]. Perm, Perm National Research Polytechnic University, 2015, $314 \mathrm{p}$.

8. Mingaleva Zh.A., Starkov Iu.V., Deputatova L.N. Model' otsenki sistemy motivatsii intellektual'noi deiatel'nosti [Model of assessment of the motivation system for the intellectual activities]. Teoriia i praktika obshchestvennogo razvitiia, 2013, no. 8, pp. 357-359. 
9. Gerchikov V.I. Upravlenie personalom: rabotnik - samyi effektivnyi resurs kompanii [Personnel management: An employee as the most effective resource of the company]. Moscow, INFRA-M, 2008, $282 \mathrm{p}$.

10. Natsypaeva E.A. Povyshenie effektivnosti sistemy nematerial'nogo stimulirovaniia organizatsii za schet razrabotki gibkogo sotsial'nogo paketa [Improving efficiency of the system of non-financial incentives through developing a system of flexible benefits package]. Vestnik Saratovskogo gosudarstvennogo sotsial'no-ekonomicheskogo universiteta, 2017, no. 1, pp. 74-76.

11. Mitrofanova A.E. Sovremennye sistemy nematerial'nogo stimulirovaniia personala organizatsii [The modern system of non-material stimulation of personnel of the organization]. Vestnik universiteta, 2016, no. 11, pp. 208-212.

12. Ot samoorganizatsii $\mathrm{k}$ samorazvitiiu: smena paradigmy menedzhmenta [From self-organization to self-development: A management paradigm shift]. Ed. S.V. Komarov. Yekaterinburg, Institute of Economics, Ural Branch of RAS, 2013, $257 \mathrm{p}$.

13. Pink D.H. Drive. The surprising truth about what motivates us (Russ. ed.: Pink D. Draiv: Chto na samom dele nas motiviruet. Moscow, Al'pina Pablisher, 2013, 274 p.).

14. El'murzaeva R.A. Realizatsiia emotsional'nogo intellekta $\mathrm{v}$ trudovoi deiatel'nosti [The implementation of emotional intelligence in working life]. Vestnik Tomskogo gosudarstvennogo universiteta. Ekonomika, 2011, no. 3(15), pp. $95-102$.

15. Panfilova A.P., Mikhal'chenko S.S. Razvitie emotsional'nogo intellekta kak sostavliaiushchei sotsial'noi kompetentnosti menedzherov [Development of emotional intellect as a component of managers' social competence]. Chelovek $i$ obrazovanie, 2013, no. 1, pp. 66-70.

16. Polianova L.M. Kontseptsii emotsional'nogo intellekta v sovremennoi praktike upravleniia [The emotional intelligence models in the modern management practices]. Teoriia i praktika obshchestvennogo razvitiia, 2015, no. 2, pp. 18-20.

17. Mingaleva Zh.A., Deputatova L.N. Primenimost' razlichnykh form motivatsii dlia stimulirovaniia truda intellektual'nykh rabotnikov [The applicability of the different forms of motivation to induce labor of knowledge workers]. Ekonomika i predprinimatel'stvo, 2013, no. 10(39), pp. 552-555.

18. Riabova M.A. Aktual'nye problemy sozdaniia effektivnoi sistemy nematerial'nogo stimulirovaniia rabotnikov promyshlennykh predpriiatii [Actual problems of creation of effective system of intangible stimulation of employees of industrial enterprises]. Upravlenie ekonomicheskimi sistemami: elektronnyi nauchnyi zhurnal, 2017, no. 1, pp. 3-5.

19. Skok S.P. Postroenie sistemy nematerial'nogo stimulirovaniia [How to motivate employees without using money]. Vestnik Omskogo universiteta. Ekonomika, 2010, no. 1, pp. 103-105. 
20. Shishkina K.A., Deputatova L.N. Sovershenstvovanie sistemy nematerial'noi motivatsii rabotnikov OOO "LUKOIL-Perm"' [Improving nonmaterial staff motivation system in Lukoil-Perm LLC]. PNRPU Sociology and Economics Bulletin, 2018, no. 1, pp. 198-209.

Оригинальность $76 \%$

Получено 25.02.2019 Принято 27.03.2019 Опубликовано 27.03.2020

\author{
L.N. Deputatova, E.A. Sevidova, E.M. Yuzkova
}

\title{
INTANGIBLE SYSTEM OF STAFF MOTIVATION AS A TOOL FOR DEVELOPING EMOTIONAL INTELLIGENCE
}

The paper studies the main approaches to the formation of human intelligence, modern models and concepts of emotional intelligence (EI). The authors define the main goal related to the formation of emotional intelligence of employees. Four main El components are described: 1 - Understanding yourself, 2 - Managing yourself, 3 - Understanding others, and 4 - Managing others. We also consider the intangible incentive system as a way to influence the emotional intelligence of employees. The authors outline a scheme of motivational management mechanism existing within any enterprise. The text analyses the principles of constructing the motivational control mechanism. It is concluded that motivation should be tuned to the interests of individual employees in order to make it effective and fully develop all the elements of the employee's EI. EI tuned out to play crucial role in any professional activity that involves communication with other people. The level of El depends on the implementation of a system of values and attitudes shared by the staff of the organization as a whole, El being an art of managing emotions for the purpose of rational work organization. The mechanism of El growth in employees depends on their desire to take initiative, ability of the head to understand the motives of other people and create the necessary conditions for the working group. A critical factor in mobilizing employees to perform the tasks facing the enterprise is the system of intangible incentives, which needs to be improved taking into account modern approaches, methods and trends of production management.

Keywords: emotional intelligence, labor motivation, labor stimulation, personnel management, non-material stimulation, motivation system.

Lyudmila N. Deputatova - Candidate of Economics Sciences, Associate Professor, Department of Economics and Industrial Production Management, Perm National Research Polytechnic University, e-mail: milade@mail.ru.

Elizaveta A. Sevidova - Undergraduate Student (Economics), Perm National Research Polytechnic University, e-mail: liza1163a@rambler.ru.

Ekaterina M. Yuzkova - Undergraduate Student (Economics), Perm National Research Polytechnic University, e-mail: katya.yuzkowa@yandex.ru.

Received 25.02.2019 Accepted 27.03.2019 Published 27.03.2020 